\title{
Glucose-induced Trehalase Activation and Trehalose Mobilization during Early Germination of Phycomyces blakesleeanus Spores
}

\author{
By JOHAN M. THEVELEIN, 1,2* ANDRÉ J. VAN LAERE, ${ }^{1}$ \\ MONIQUE BEULLENS, ${ }^{1}$ JOZEF A. VAN ASSCHE ${ }^{1}$ AND \\ ALBERT R. CARLIER ${ }^{1}$ \\ ${ }^{1}$ Laboratorium voor Plantenbiochemie, Katholieke Universiteit te Leuven. Kardinaal \\ Mercierlaan 92, B-3030 Heverlee, Belgium \\ ${ }^{2}$ Department of Molecular Biophysics and Biochemistry, Yale University, Box 6666 Yale Station, \\ New Haven, CT 06511, U.S.A.
}

(Received 17 June 1982; revised 1 September 1982)

\begin{abstract}
When dormant spores of Phycomyces blakesleeanus were activated without concomitant activation of trehalase, breakdown of storage trehalose during early germination was not prevented. Measurement of trehalase activity during early germination of spores activated in this way indicated a subsequent rapid activation of trehalase upon incubation of the spores in germination medium. Trehalase activity reached a maximum after about $10 \mathrm{~min}$ of germination; thereafter it declined to values somewhat higher than those found in dormant spores. The same was observed when the activation of trehalase which normally occurs during heat activation of the spores was suppressed by adding long-chain alcohols to the activation medium. These results argue against previous speculation that trehalase is a 'luxury' molecule in the spores and that its activation has no significant role in the induction of germination. They point, on the other hand, to an important role for trehalase in the induction of germination. The main factor in the germination medium responsible for the activation of trehalase was found to be glucose. When spores were incubated under conditions in which they reverted to the dormant state, this subsequent trehalase activation was not seen. The increase in trehalase activity was not dependent on protein synthesis. A less pronounced increase was seen with glucose analogues. In the presence of azide the activation was only retarded, whereas in the presence of azide and salicylhydroxamic acid strong inhibition of trehalase activation was observed.
\end{abstract}

\section{INTRODUCTION}

Germination of the spores of Phycomyces blakesleeanus can be induced by a short heat shock ( $3 \mathrm{~min}, 50^{\circ} \mathrm{C}$ ) (Robbins et al., 1942; Sommer \& Halbsguth, 1957). This heat activation normally results in a simultaneous activation of the enzyme trehalase in the spores (Van Assche $e t$ al., 1972). The sudden increase in trehalase activity upon activation of the spores has always been assumed to be responsible for the greatly enhanced trehalose breakdown during spore germination. Such an increase in trehalose breakdown seems to be a universal and important phenomenon in fungal spore germination (Lingappa \& Sussman, 1959; Mandels et al., 1965; Horikoshi \& Ikeda, 1966; Ceccarini, 1967; Daly et al., 1967; Rudolph \& Ochsen, 1969; Aitken \& Niederpruem, 1972; Rousseau et al., 1972). Short-term increases in trehalase activity have been found only for $P$. blakesleeanus spores upon heat activation and recently also during early germination of yeast ascospores (Thevelein et al., 1982). Increases in trehalase activity after several hours of germination have been found for spores of Dictyostelium discoideum (Ceccarini, 1967; Cotter \& Raper, 1970) and related species (Tisa \& Cotter, 1979), Streptomyces hygroscopicus (Hey-Ferguson et al., 1973) and Aspergillus oryzae (Horikoshi \& Ikeda, 1966). In the case of $D$. discoideum spores, as opposed to $P$. blakesleeanus spores, the increase in trehalase activity was shown to be dependent on protein synthesis (Cotter \& Raper, 1970). 
From our previous experiments on trehalase activation during spore heat activation, it has become clear that the activation of trehalase is not the primary triggering mechanism of spore heat activation (Van Assche et al., 1978; Thevelein et al., 1980, 1981 b). Also, evidence has been obtained for the involvement of different mechanisms in the two phenomena: a protein conformational change is involved in the spore activation process (Thevelein et al., 1979), whilst for trehalase activation all available evidence points to a structural transition in a polysaccharide layer as the triggering mechanism (Thevelein et al., 1981 $a, b$ ).

Several methods enable activation of $P$. blakesleeanus spores to be achieved without simultaneous activation of trehalase: activation with reducing substances, e.g. $\mathrm{Na}_{2} \mathrm{~S}_{2} \mathrm{O}_{4}$ (Van Assche et al., 1978), addition of long-chain n-alcohols during heat activation (Thevelein $e t$ al., $1981 b$ ) and heat activation under high pressure (Thevelein et al., 1980). Hence, the question was raised whether spores activated in this way were germinating without using their endogenous trehalose reserve. This question, and the activation of trehalase during early germination, are the subject of this paper.

\section{METHODS}

Organism, culture method and harvesting of the spores. Strain $\mathrm{K}^{+}$(formerly $1^{+}$) of Phycomyces blakesleeanus Burgeff, from the collection of W. Halbsguth, was cultured on sterile moistened brown bread in the dark at $18^{\circ} \mathrm{C}$ and $70 \%$ relative humidity. Spores were harvested, dried and stored for a maximum of 2 weeks as described previously (Van Assche et al., 1972).

Activation. Heat activation was carried out as follows: $20 \mathrm{mg}$ (dried) spores were heated for $3 \mathrm{~min}$ in $1 \mathrm{ml} 0 \cdot 01 \mathrm{M}$ potassium phosphate buffer, $\mathrm{pH} \mathrm{6.5}$. Temperature of heat treatment and addition of $\mathrm{n}$-alcohols are described in the legends to the appropriate figures. After the heat treatment, the spores were cooled in an ice bath, collected by centrifugation and washed twice with distilled water.

Activation with dithionite $\left(\mathrm{Na}_{2} \mathrm{~S}_{2} \mathrm{O}_{4}\right)$ was carried out as follows: 50,60 or $70 \mathrm{mg} \mathrm{Na} \mathrm{S}_{2} \mathrm{O}_{4}$ were dissolved in $100 \mathrm{ml}$ water just before use; $20 \mathrm{mg}$ spores were shaken at room temperature in $1 \mathrm{ml}$ of the $\mathrm{Na}_{2} \mathrm{~S}_{2} \mathrm{O}_{4}$ solution for the time indicated in the figure legends. For pyrosulphite activation $20 \mathrm{mg}$ spores were shaken for $15 \mathrm{~min}$ in $1 \mathrm{ml}$ of freshly prepared $0.05 \%(\mathrm{w} / \mathrm{v}) \mathrm{Na}_{2} \mathrm{~S}_{2} \mathrm{O}_{5}$. At the end of the activation treatment, the spore suspension was immediately diluted 15 -fold with cold distilled water, and the spores were collected by centrifugation and washed once more.

Germination percentages. A sample volume corresponding to $2 \mathrm{mg}$ spores was taken after the activation treatment and transferred to minimal nutrient medium. Germination percentages were determined under the microscope after $8 \mathrm{~h}$ incubation at room temperature in minimal nutrient medium. The spore suspensions were incubated in a reciprocating shaker at a concentration of $2 \mathrm{mg}$ spores $\mathrm{ml}^{-1}$. Usually, a total of 200-300 spores was counted. The composition of the minimal nutrient medium was as described by Rudolph (1958).

Trehalase assay. Spores were allowed to germinate in minimal nutrient medium in a reciprocating shaker. Samples were taken at the indicated times and the spores washed once. (In these experiments the first value always represents the trehalase activity measured as soon as possible after the activation treatment, before resuspension in minimal nutrient medium.)

The crude enzyme extract was prepared as follows: spores were suspended in $1.5 \mathrm{ml}$ homogenization buffer ( $0.01 \mathrm{M}$-potassium phosphate, $\mathrm{pH} 6.5)$. They were then transferred to a pre-cooled $7 \mathrm{ml}$ Teflon container containing $3.3 \mathrm{ml}$ glass beads of $1 \mathrm{~mm}$ diameter and $1.2 \mathrm{ml}$ glass beads of $3 \mathrm{~mm}$ diameter. The spores were broken by vibration in a Braun (Melsungen, F.R.G.) microdismembrator II ( $4 \mathrm{~min}$, amplitude $5 \mathrm{~mm}$ ). The crude enzyme extract was centrifuged for $4 \mathrm{~min}$ at $10000 \mathrm{~g}$ in an Eppendorf microcentrifuge. The supernatant was dialysed at $4{ }^{\circ} \mathrm{C}$ for several hours against $5 \mathrm{~mm}$-potassium phosphate buffer, $\mathrm{pH} 7 \cdot 5$.

A $20 \mu \mathrm{l} \mathrm{sample} \mathrm{of} \mathrm{the} \mathrm{dialysed} \mathrm{crude} \mathrm{enzyme} \mathrm{extract} \mathrm{was} \mathrm{added} \mathrm{to} 100 \mu \mathrm{l} 0 \cdot 1 \mathrm{M}$-trehalose $+0 \cdot 1 \mathrm{M}$-potassium phosphate buffer, $\mathrm{pH} 7.5$, and $130 \mu \mathrm{l}$ water was added, to give a final volume of $0.25 \mathrm{ml}$. One sample was boiled immediately for $3 \mathrm{~min}$ to give the blank value. Two other samples were incubated for $30 \mathrm{~min}$ at $30^{\circ} \mathrm{C}$ and then boiled for $3 \mathrm{~min}$ (Van Assche et al., 1972). The amount of glucose liberated in the samples was measured by the glucose oxidase-peroxidase method (Lloyd \& Whelan, 1969). The specific activity of trehalase is expressed as nmol glucose liberated $\min ^{-1}$ (mg protein) $)^{-1}$.

Protein determination. Protein content was determined by the Lowry method.

Determination of trehalose. In each experiment $20 \mathrm{mg}$ spores were used. After activation, the spores were allowed to germinate in minimal nutrient medium in a reciprocating shaker at a spore concentration of $2 \mathrm{mg} \mathrm{ml}^{-1}$. Samples were taken at the indicated times and the spores washed once. (In these experiments, the first value always represents the trehalose content measured as soon as possible after the activation treatment, before resuspension in minimal nutrient medium.) After washing, the spores were boiled in $2 \mathrm{ml} 80 \%(\mathrm{v} / \mathrm{v})$ ethanol and homogenized with the Braun microdismembrator II, as described above. 
The ethanol-insoluble material was removed by centrifugation and washed several times with $80 \%(\mathrm{v} / \mathrm{v})$ ethanol. All supernatants were combined and evaporated to dryness. Lipids were removed from the ethanolsoluble material by treatment with chloroform. The water-soluble fraction was dissolved in distilled water. The neutral fraction was separated from basic and acidic fractions by means of the ion exchangers Dowex $-50-\mathrm{H}^{+}$and Dowex-1-Ac- (Carlier \& Van Laere, 1972).

In dormant spores, the neutral fraction consists mainly of trehalose, in activated spores mainly trehalose, glucose and glycerol are found. Trehalose was separated from the other carbohydrates by HPLC (Waters Associates, Milford, Conn., U.S.A.). The column was filled with Lichrosorb- $\mathrm{NH}_{2}, 5 \mu \mathrm{m}$. The solvent was $75 \%$ $(\mathrm{v} / \mathrm{v})$ acetonitrile in water and the flow rate was $2 \mathrm{ml} \mathrm{min}^{-1}$. The amount of trehalose was measured with a refractometer and quantified with a Hewlett-Packard integrator model 3385A. An external trehalose standard was used for calibration.

\section{RESULTS}

Dormant spores of Phycomyces blakesleeanus slightly increased their trehalose content during incubation in the minimal nutrient medium, which was normally used as germination medium (Fig. $1 \mathrm{a}$ ). Spores activated by a heat shock of $3 \mathrm{~min}$ at $50^{\circ} \mathrm{C}$ underwent considerable breakdown of internal trehalose during subsequent germination in minimal nutrient medium at room temperature (Fig. 1 $a$; Rudolph \& Ochsen, 1969). Spores activated in this way showed a rapid increase in trehalase activity during the heat shock; the activity increased slightly further during early germination and gradually declined thereafter (Fig. 1 b). Spores of $P$. blakesleeanus can also be activated to a considerable extent by dithionite. No increase in trehalase activity was seen during such an activation treatment (Van Assche et al. 1978; Fig. 2). However, breakdown of trehalose was still apparent during subsequent germination (Fig. 1a). When the spores were allowed to germinate, trehalase activity increased quickly in the early phase of germination, afterwards declining to low values (Fig. 2).

When trehalase activation during spore heat activation was suppressed by addition of a longchain alcohol to the activation medium, only low activity was seen after the heat activation, but when the spores were suspended in germination medium trehalase activity increased at least 20fold, within $5 \mathrm{~min}$ (Fig. 3). Afterwards, the activity gradually returned to values somewhat higher than the low values found for dormant spores. In the experiment shown in Fig. 3(a), trehalase activation during spore heat activation was suppressed with $40 \mathrm{~mm}$-hexanol, in that shown in Fig. 3(b) with $10 \mathrm{~mm}$-heptanol. The extent of the increase in trehalase activity
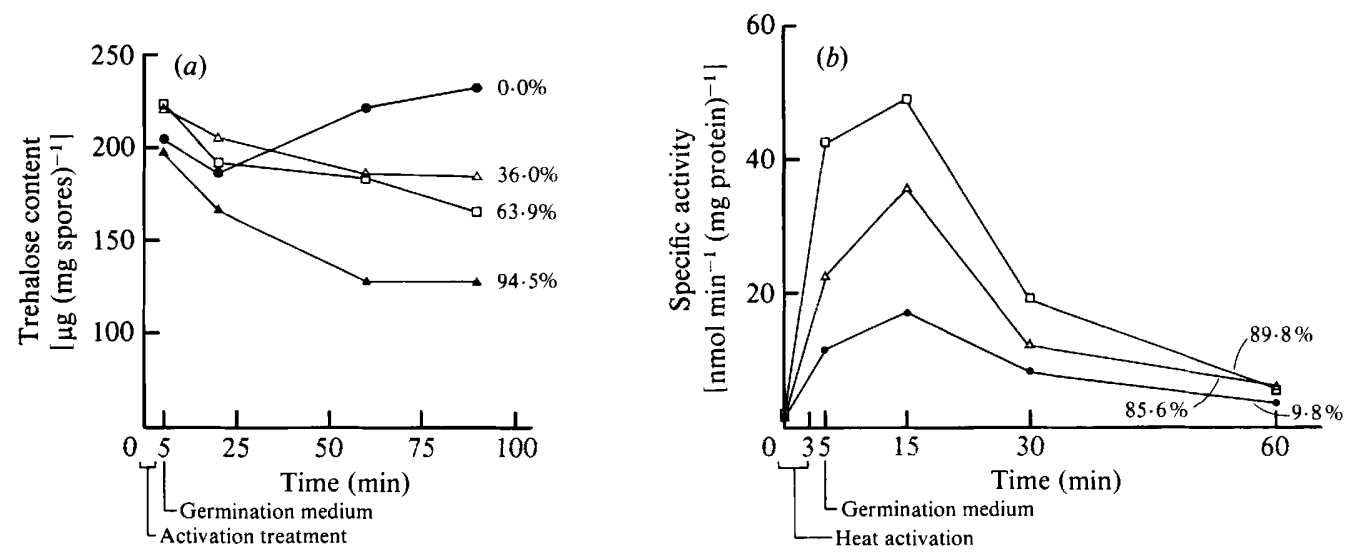

Fig. 1. (a) Trehalose content during germination (germination percentages are indicated on the figure). , Control, dormant spores $\left(0.0 \%\right.$ germination); $\triangle$, spores activated with $\mathrm{Na}_{2} \mathrm{~S}_{2} \mathrm{O}_{4}\left(0.5 \mathrm{mg} \mathrm{ml}^{-1}\right.$, $3 \mathrm{~min})\left(36.0 \%\right.$ germination); $\square$, spores activated with $\mathrm{Na}_{2} \mathrm{~S}_{2} \mathrm{O}_{4}\left(0.7 \mathrm{mg} \mathrm{ml}^{-1}, 2 \mathrm{~min}\right)(63.9 \%$ germination); $\boldsymbol{A}$, heat-activated spores $\left(3 \mathrm{~min}\right.$ at $\left.50{ }^{\circ} \mathrm{C}\right)(94.5 \%$ germination). (b) Trehalase activity after heat activation for 3 min at various temperatures and during subsequent germination (at room temperature). Activation was at: $42{ }^{\circ} \mathrm{C}(0,9.8 \%$ germination $), 46^{\circ} \mathrm{C}(\triangle, 85.6 \%$ germination $)$, or $50{ }^{\circ} \mathrm{C}$ ( $\square, 89 \cdot 8 \%$ germination). 


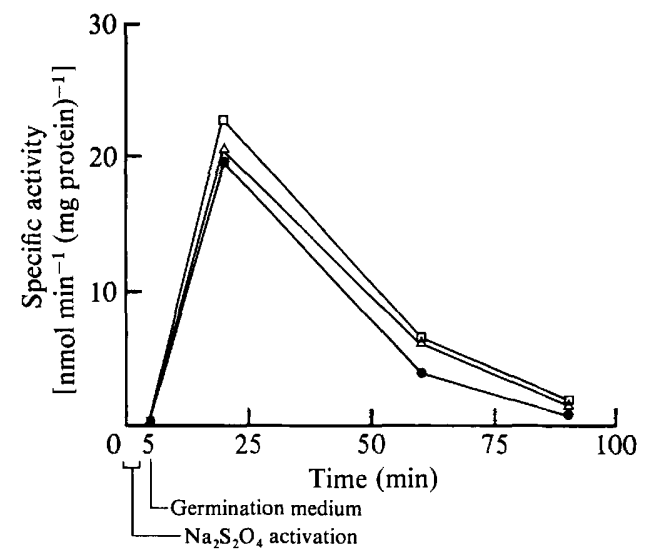

Fig. 2. Trehalase activity during germination after spore activation with $\mathrm{Na}_{2} \mathrm{~S}_{2} \mathrm{O}_{4}$ at $0.5 \mathrm{mg} \mathrm{ml}^{-1}$ for 3 $\min \left(0,36.0 \%\right.$ germination), at $0.6 \mathrm{mg} \mathrm{ml}^{-1}$ for $3 \mathrm{~min}\left(\triangle, 38.9 \%\right.$ germination), or at $0.7 \mathrm{mg} \mathrm{ml}^{-1}$ for $2 \min (\square, 63.9 \%$ germination).
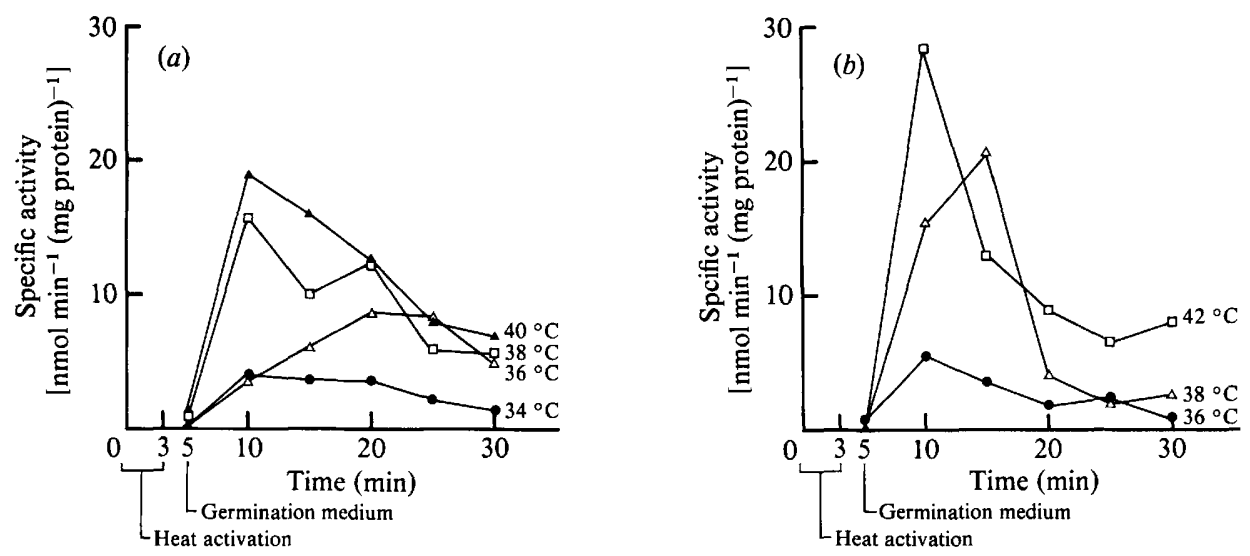

Fig. 3. Trehalase activity during germination (at room temperature) after initial suppression of trehalase activation with (a) $40 \mathrm{~mm}$-hexanol during spore heat activation at $34^{\circ} \mathrm{C}(\boldsymbol{0}, 7.5 \%$ germination), $36^{\circ} \mathrm{C}\left(\triangle, 32 \cdot 6 \%\right.$ germination), $38{ }^{\circ} \mathrm{C}\left(\square, 70.0 \%\right.$ germination), or $40{ }^{\circ} \mathrm{C}(\boldsymbol{\Delta}, 56.4 \%$ germination); and (b) $10 \mathrm{~mm}$-heptanol during spore heat activation at $36^{\circ} \mathrm{C}(\mathbf{0}, 11.9 \%$ germination), $38{ }^{\circ} \mathrm{C}(\triangle, 59 \cdot 4 \%$ germination $)$, or $42^{\circ} \mathrm{C}(\square, 67 \cdot 3 \%$ germination $)$.

depends, in part, on the germination percentage; the higher it is, the higher the trehalase activity. However, trehalase activity still increased when spore germination percentages started to decrease because of the onset of spore killing at higher temperatures (Fig. 3). This was observed previously for trehalase activation during normal spore heat activation (Thevelein $e t$ $a l ., 1981 b$ ).

Figure 4 shows that for activation with pyrosulphite also, trehalase activity did not increase during the activation treatment, but did increase during subsequent germination. As was observed previously for trehalase activation during spore heat activation (Van Assche et al., 1972), the increase was not strongly inhibited by cycloheximide, indicating that the effect is not dependent on protein synthesis (Fig. 4).

The increase in trehalase activity did not occur when the spores were incubated in water. When the components of the culture medium were tested separately it was found that glucose was necessary for an increase in trehalase activity. When added with glucose, the other components (phosphate, asparagine and salts) produced some additional stimulation (Fig. 5). Similar results were found when the components of the culture medium were tested for their 


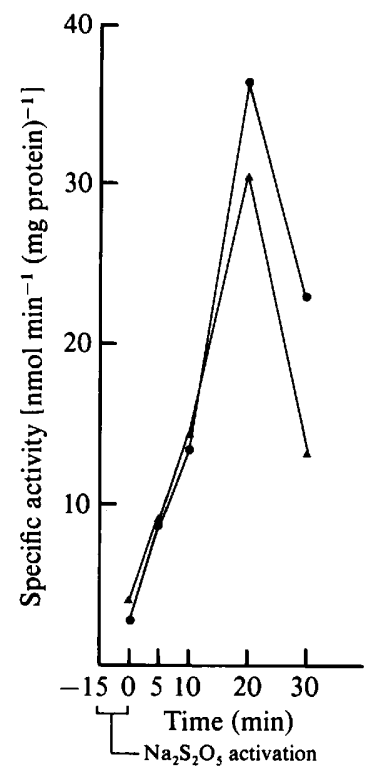

Fig. 4. Specific activity of trehalase after spore activation (germination about $70 \%$ ) with $\mathrm{Na}_{2} \mathrm{~S}_{2} \mathrm{O}_{5}$ at $0.5 \mathrm{mg} \mathrm{ml}^{-1}$ for $15 \mathrm{~min}$ and during subsequent incubation in either minimal nutrient medium (O) or minimal nutrient medium supplemented with cycloheximide at $20 \mu \mathrm{g} \mathrm{ml}^{-1}(\boldsymbol{\Lambda})$.

effect in promoting germination of the spores, i.e., spores incubated in water reverted to the dormant state and glucose was the main component of the germination medium which prevented this (Van Laere et al., 1980a).

Other compounds such as fructose, trehalose, maltose, glycerol or glutamine, together with phosphate, yielded at most a slight increase in trehalase activity (data not shown). However, in the presence of 2-deoxyglucose a less pronounced but clear increase in trehalase activity occurred. With 3-O-methylglucose and methyl $\alpha$-D-glucopyranoside only very slight stimulation of the trehalase activity was seen (Fig. 6). 2-Deoxyglucose can be metabolized to a limited extent by $P$. blakesleeanus spores. When spores were provided with labelled 2-deoxyglucose, a considerable amount of label was recovered in cell wall material and probably also in deoxytrehalose (A. Van Laere, unpublished results), indicating that metabolism via nucleoside diphosphate sugars was possible. Yeast has also been found to synthesize 2-deoxytrehalose and cell wall material from 2-deoxyglucose (Farkas et al., 1969, Zemek \& Bauer, 1972).

The increase in trehalase activity was not inhibited but only retarded in the presence of azide (data not shown). Since $P$. blakesleeanus spores can also respire by an azide-insensitive pathway (Van Laere et al., $1980 a$ ) the effect of salicylhydroxamic acid (SHAM), an inhibitor of the alternative respiration pathway, was tested. SHAM alone had a slight inhibitory effect. However, in combination with azide the increase in trehalase activity was strongly inhibited (data not shown). In these conditions respiration is nearly completely blocked (Van Laere et al., $1980 a)$.

\section{DISCUSSION}

Several spore activation methods have been found which do not result in an activation of trehalase until after the activation treatment (e.g. Van Assche et al., 1977; Van Assche et al., 1978; Van Laere et al., 1980 b). On the other hand, activation of $P$. blakesleeanus spores by heat treatment and by acetate results in greatly increased trehalase activity during the activation treatment itself (Van Assche et al., 1972; Delvaux, 1973).

The relation between trehalase activation and trehalose breakdown has not been investigated previously. Since it was possible to activate $P$. blakesleeanus spores without activation of 


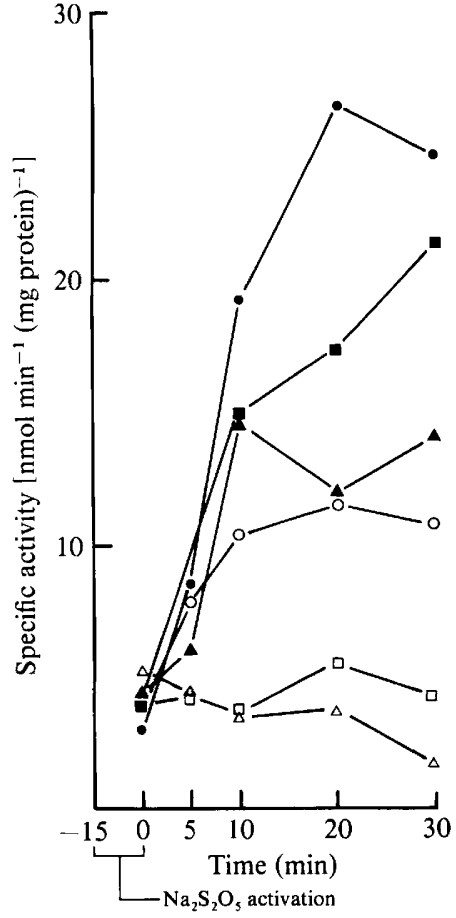

Fig. 5

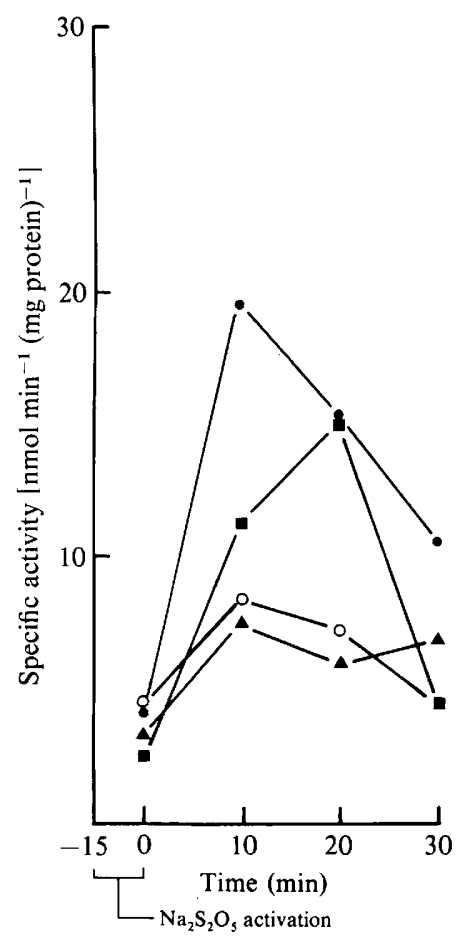

Fig. 6

Fig. 5. Specific activity of trehalase after spore activation (germination about $70 \%$ ) with $\mathrm{Na}_{2} \mathrm{~S}_{2} \mathrm{O}_{5}$ at $0.5 \mathrm{mg} \mathrm{ml} \mathrm{m}^{-1}$ for $15 \mathrm{~min}$ and during subsequent incubation in water $(\triangle), 10 \mathrm{mM}-\mathrm{KH}_{2} \mathrm{PO}_{4}(\square), 83 \mathrm{mM}$ glucose (O), $83 \mathrm{~mm}$-glucose and $10 \mathrm{~mm}-\mathrm{KH}_{2} \mathrm{PO}_{4}(\mathrm{~A}), 83 \mathrm{~mm}$-glucose, $10 \mathrm{~mm}-\mathrm{KH}_{2} \mathrm{PO}_{4}$ and $0 \cdot 1 \%$ asparagine $(\boldsymbol{\square})$, or complete minimal medium (O).

Fig. 6. Specific activity of trehalase after spore activation (germination about $60 \%$ ) with $\mathrm{Na}_{2} \mathrm{~S}_{2} \mathrm{O}_{5}$ at $0.5 \mathrm{mg} \mathrm{ml}^{-1}$ for $15 \mathrm{~min}$ and during subsequent incubation in $10 \mathrm{mM}-\mathrm{KH}_{2} \mathrm{PO}_{4}$ supplemented with glucose (O), 2-deoxy-D-glucose ( $\square$ ), methyl $\alpha$-D-glucopyranoside (O), or 3-O-methylglucoside $(\boldsymbol{\Lambda})$ (each at $83 \mathrm{~mm}$ ).

trehalase, three possibilities could be distinguished for the relation between spore germination and trehalose breakdown: (i) the spores were germinating without using their endogenous trehalose reserve; (ii) there was no relation between trehalase activation and trehalose breakdown [and hence, either the basal trehalase level found in dormant spores was sufficient to maintain trehalose breakdown or trehalose was broken down in another way (see, for example, Belocopitow and Maréchal, 1970; Bhumiratana et al., 1974)]; (iii) trehalase became activated later on during germination. As can be seen from Figs 2 and 4, the third possibility was the correct one. When spore germination was induced by a method that does not result in immediate activation of trehalase, the enzyme subsequently became activated during the initial stages of germination. A similar increase in trehalase activity during subsequent germination was observed when the initial activation of the enzyme, which normally occurs during heat activation of the spores, had been suppressed by addition of a long-chain alcohol to the activation medium (Fig. 3).

The main component in the germination medium responsible for the activation of trehalase was glucose. It is also responsible for preventing the spores from returning to the dormant state after they have been heat activated (Van Laere et al., 1980a). Hence, breakdown of the endogenous trehalose reserve in the spores, brought about by the activation of trehalase, could be responsible for the induction of the initial steps of germination, also making it difficult for the spores to return to the dormant state, as suggested previously (Van Laere et al., 1980a). These results, and the fact that trehalase is activated in spite of the high glucose concentration present 
in the medium, strongly argue against previous speculation that trehalase merely represents a 'luxury' molecule in the spore and that its activation has no significant role in the induction of germination (Van Assche et al., 1977, 1978; Van Laere et al., 1980 b). The fact that high trehalase activity correlated with difficulty in regaining the dormant state, and that artificial suppression of trehalase during spore heat activation was followed by activation of trehalase during early germination, points to an important role for trehalase in the process of germination. However, the amount of glucose made available from trehalose hydrolysis does not seem to be sufficient to support germination beyond its initiation. An additional exogenous carbon source is required for germination to continue.

In the presence of cycloheximide germination is inhibited at an early stage: only slight swelling of the spores is observed and the increase in respiratory activity is nearly completely blocked (Van Laere et al., 1976). As the activation of trehalase was not prevented by cycloheximide, it must be linked to an even earlier stage of the germination process.

Activation of trehalase and germination showed similar substrate dependence. Substrates other than glucose (fructose, maltose, trehalose, glycerol, glutamine), which only result in low stimulation of trehalase activity, are also poor substrates during early germination (Van Laere \& Carlier, 1977; Van Assche et al., 1978). Acetate, which is an efficient spore activator, is a good substrate for spore germination and also causes a strong increase in trehalase activity (Borchert, 1962; Delvaux, 1973; Van Laere et al., 1980b).

The stimulation of $P$. blakesleeanus trehalase activity by 2-deoxyglucose contrasts with the situation in yeast ascospores (Thevelein et al., 1982), where 2-deoxyglucose does not stimulate trehalase activity. This suggests a more direct involvement of glucose in trehalase activation in $P$. blakesleeanus.

Recently, it has been found that trehalase becomes activated in yeast ascospores in a similar way to that in $P$. blakesleeanus spores upon suspension of the spores in a medium containing glucose (and a minimal amount of phosphate) (Thevelein et al., 1982). However, in contrast to $P$. blakesleeanus spores, yeast spores do not need an activation treatment, such as a heat treatment, before germination can be induced by addition of glucose and phosphate. The fact that yeast ascospores show the same dependency as $P$. blakesleeanus spores on glucose (and phosphate) for germination, trehalase activation and trehalose breakdown suggests that spore activation and germination induction are two different processes.

J. M. Thevelein and A. J. Van Laere gratefully acknowledge receipt of a fellowship from the Belgian National Fund for Scientific Research.

\section{REFERENCES}

AITKEN, W. B. \& NiederPRuEM, D. J. (1972). Isotopic studies of carbohydrate metabolism during basidiospore germination in Schizophyllum commune. I. Uptake of radioactive glucose and sugar alcohols. Archiv für Mikrobiologie 82, 173-183.

Belocopitow, E. \& MARÉchal, L. R. (1970). Trehalose phosphorylase from Euglena gracilis. Biochimica et biophysica acta 198, 151-154.

Bhumiratana, A., Anderson, R. L. \& Costilow, R. N. (1974). Trehalose metabolism by Bacillüs popilliae. Journal of Bacteriology 119, 484-493.

BORCHERT, R. (1962). Über die Azetat-Aktivierung der Sporangiosporen von Phycomyces blakesleeanus. Beiträge zur Biologie der Pflanzen 38, 31-61.

Carlier, A. R. \& Van Laere, A. J. (1972). The fate of label from glucose-U $-{ }^{14} \mathrm{C}$ during incubation and chase experiments in mung bean tissue. An approach to the problem of dilution and compartmentation. Zeitschrift für Pflanzenphysiologie 68, 63-72.
CeCCARINI, C. (1967). The biochemical relationship between trehalose and trehalase during growth and differentiation in the cellular slime mold, Dictyostelium discoideum. Biochimica et biophysica acta 148, 114-124.

Cotter, D. A. \& RAPER, K. B. (1970). Spore germination in Dictyostelium discoideum: trehalase and the requirement for protein synthesis. Developmental Biology 22, 112-128.

DALY, J. M., KNOCHE, H. W. \& WIESE, M. V. (1967). Carbohydrate and lipid metabolism during germination of uredospores of Puccinia graminis tritici. Plant Physiology 42, 1633-1642.

Delvaux, E. (1973). Some aspects of germination induction in Phycomyces blakesleeanus by an ammonium acetate pretreatment. Archiv für Mikrobiologie 88, 273-284.

FARKAS, V., BAUER, S. \& ZEMEK, J. (1969). Metabolism of 2-deoxy-D-glucose in baker's yeast. III. Formation 
of 2,2'-dideoxy- $\alpha, \alpha^{\prime}$-trehalose. Biochimica et biophysica acta 184, 77-82.

Hey-Ferguson, A., Mrtchell, M. \& Elbein, A. D. (1973). Trehalose metabolism in germinating spores of Streptomyces hygroscopicus. Journal of Bacteriology 116, 1084-1085.

HoRIKoshI, K. \& IKEDA, Y. (1966). Trehalase in conidia of Aspergillus oryzae. Journal of Bacteriology 91, 1883-1887.

LingaPPa, Y. \& Sussman, A. S. (1959). Changes in the heat-resistance of ascospores of Neurospora upon germination. American Journal of Botany 46, 671678.

LlOYD, J. B. \& WhelaN, W. J. (1969). An improved method for enzymic determination of glucose in the presence of maltose. Analytical Biochemistry 30, 467470.

Mandels, G. R., Vitols, R. \& Parrish, F. W. (1965). Trehalose as an endogenous reserve in spores of the fungus Myrothecium verrucaria. Journal of Bacteriology 90, 1589-1598.

Robbins, W. J., Kavanagh, V. W. \& Kavanagh, F. (1942). Growth substances and dormancy of spores of Phycomyces. Botanical Gazette 104, 224-242.

Rousseau, P., Halvorson, H. O., Bulla, L. A. \& JULIAN, G. S. (1972). Germination and outgrowth of single spores of Saccharomyces cerevisiae viewed by scanning electron and phase-contrast microscopy. Journal of Bacteriology 109, 1232-1238.

RUDOLPH, H. (1958). Entwicklungsphysiologische Untersuchungen an den Sporangiophoren von Phycomyces blakesleeanus. Biologisches Zentralblatt 77, 385-437.

RUDOLPH, H. \& OCHSEN, B. (1969) Trehalose-Umsatz wärmeaktivierter Sporen von Phycomyces blakesleeanus. Archiv für Mikrobiologie 65, 163-171.

SOMMER, L. \& HalBsGUTH, W. (1957). Grundlegende Versuche zur Keimungsphysiologie von Pilzsporen. Forschungsberichte des Wirtschafts- und Verkehrsministeriums, Nordrhein-Westfalen No. 411.

Thevelein, J. M., Van Assche, J. A., Carlier, A. R. \& Heremans, K. (1979). Heat activation of Phycomyces blakesleeanus spores: thermodynamics and effect of alcohols, furfural and high pressure. Journal of Bacteriology 139, 478-485.

Thevelein, J. M., Van Assche, J. A. \& Heremans, K. (1980). Effect of high pressure on the heat activation in vivo of trehalase in the spores of Phycomyces blakesleeanus. European Journal of Biochemistry 111, 171-175.

Thevelein, J. M., Van Assche, J. A., Heremans, K. \& GerLSMA, S. Y. (1981a). Gelatinisation temperature of starch, as influenced by high pressure. Carbohydrate Research 93, 304-307.
Thevelein, J. M., Van Assche, J. A., Heremans, K., Gerlsma, S. Y. \& Carlier, A. R. (1981 b). Trehalase activity in extracts of Phycomyces blakesleeanus spores following the induction of germination by heat activation. Antonie van Leeuwenhoek 47, 393404.

Thevelein, J. M., den Hollander, J. A. \& Shulman, R. G. (1982). Changes in the activity and properties of trehalase during early germination of yeast ascospores. Correlation with trehalose breakdown as studied by in vivo ${ }^{13} \mathrm{C}$ NMR. Proceedings of the National Academy of Sciences of the United States of America 79, 3503-3507.

TisA, L. S. \& CotTeR, D. A. (1979). Trehalase expression during the germination of three resting stages of the Dictyosteliaceae. Current Microbiology 3, 33-35.

Van Assche, J. A., Carlier, A. R. \& DekeErsmaeker, H. I. (1972). Trehalase activity in dormant and activated spores of Phycomyces blakesleeanus. Planta 103, 327-333.

Van Assche, J. A., Carlier, A. R. \& Van Tieghem, L. L. C. (1977). The effect of gamma radiation on breaking of dormancy in Phycomyces spores. Archives of Microbiology 113, 95-97.

VAN Assche, J. A., VAN Laere, A. J. \& CARLIER, A. R. (1978). Trehalose metabolism in dormant and activated spores of Phycomyces blakesleeanus Burgeff. Planta 139, 171-176.

VAN LAERe, A. J. \& CARLIER, A. R. (1977). Decarboxylation of gluconic acid and fructose by dormant and activated spores of Phycomyces blakesleeanus Burgeff. Biochemie und Physiologie der Pflanzen 171, 151-156.

Van Laere, A. J., Carlier, A. R. \& Van Assche, J. A. (1976). Effect of 5-fluorouracil and cycloheximide on the early development of Phycomyces blakesleeanus spores and the activity of $\mathrm{N}$-acetylglucosamine synthesizing enzymes. Archives of Microbiology 108, 113-116.

Van Laere, A. J., Van Assche, J. A. \& Carlier, A. R. $(1980 a)$. Reversible and irreversible activation of Phycomyces blakesleeanus spores. Experimental Mycology 4, 96-104.

Van Laere, A. J., Van Assche, J. A. \& Carlier, A. R. $(1980 \mathrm{~b})$. Metabolism and chemical activation of Phycomyces blakesleeanus spores. Experimental Mycology 4, 260-268.

ZEMEK, J. \& BAUER, S. (1972). Metabolism of 2-deoxyD-glucose in baker's yeast. V. Formation of 2-deoxy$\alpha, \alpha^{\prime}$-trehalose. Biochimica et biophysica acta 264, 393397. 